\title{
HSCT FOR ACUTE MYELOID LEUKEMIA
}

Lúcia Silla L ${ }^{1}$, Adriano Arantes ${ }^{2}$, Claudia Astigarraga ${ }^{1,3}$, Karine Sampaio Nunes Barroso ${ }^{4}$, Miriam Perlingeiro Beltrame ${ }^{5}$, Gustavo Bettarello ${ }^{6}$, Paulo Campregher ${ }^{7}$, Fernando Barroso Duarte ${ }^{4}$, Vaneuza Araújo Moreira Funke ${ }^{8}$, Felipe Magalhães Furtado ${ }^{9,10}$, Nelson Hamerschlak ${ }^{11}$, Maura Rosane Valéria Ikoma Colturato ${ }^{12}$, Eduardo José de Alencar Paton ${ }^{13}$, Beatriz Stela Gomes de Souza Pitombeira ${ }^{4}$, Elisabeth Xisto Souto ${ }^{14,15}$, Margareth Afonso Torres ${ }^{7}$.

1.Hospital de Clínicas de Porto Alegre - 2.Hospital Órion - Einstein Gestão Hospitalar - 3.Hospital Mounhos de Vento 4. Hospital Universitário Walter Cantídio - 5.Hospital Erasto Gaertner-Curitiba - 6.Oncologia D'Or - 7.Hospital Israelita Albert Einstein - 8.Hospital de Clínicas do Paraná - 9.Sabin Medicina Diagnóstica - 10.Hospital da Criança de Brasília José de Alencar 11.Hospital Israelita Albert Einstein - 12.Hospital Amaral Carvalho - 13.Oncoclinica - 14. Hospital Brigadeiro / Hospital de transplantes Euryclides de Jesus Zerbini - 15.Hospital do Câncer de Barretos/ Hospital de Amor

In the last few years, there were several developments in the field of hematopoietic stem cell transplantation (HSCT) for acute myeloid leukemia (AML). The approval of new target drugs and the mounting clinical experience also with the epigenetics agents, leaded to an increase in response rates for the mainly elderly population of patients. These drugs have a safer profile than high dose chemotherapy; aggressive infections treated with an array of toxic medicines and its related side effects are less frequently observed with these drugs, enabling the patient to be forwarded to HSCT in a better clinical condition. On the other hand, less toxic conditioning regimens designed for this fragile population of patients, and donor availability have changed for the better HSCT outcomes. Utilizing an haploidentical donors makes it easier to find a donor - frequently among a younger progeny. Pos transplant cyclophosphamide (Cy) as a major graft versus host disease (GVHD) prophylaxis is effective and have been successfully tested in other HLA donor-recipient combinations, in particular, in the mismatch unrelated HSCT scenario. Finally, the increasingly robust data about the impact of the presence of minimal residual disease (MRD) after remission induction that can predict HSCT outcome, is improving patient selection.

In the US and some of the Brazilian Transplantation Centers, AML is the leading indication for Allogeneic
HSCT. HSCT still is the gold standard for intermediate and adverse risk AML. In addition to the new developments outlined above, the widespread utilization of disease's and patient's risk categorization as well as the above-mentioned increased utilization of less toxic conditioning regimens, both myeloablative and reduced intensity (RIC), have improved SCT outcomes over the years. ${ }^{[1-3]}$

Finally, the indication for HSCT should be at AML diagnosis, taking into consideration disease risk, patient risk (such as age and possible comorbidities), as well as donor type (related, unrelated, age and gender). It is never too much to outline that HSCT is indicated when the risk of relapse is higher than the risk of transplant related mortality (TRM).

\section{SCT FOR AML IN FIRST COMPLETE REMISSION}

European Leukemia Net (ELN)4 recommendations based in karyotypic and molecular abnormalities are widely accepted and validated for AML risk stratification. (Table 1)

Intermediate and adverse risk AML should be transplanted at first complete remission (CR) provided that factors such as patient's risk or TRM chances are weighted. ${ }^{[5-7]}$ 
TABLE 1 - ELN AML risk stratification

\begin{tabular}{|c|c|}
\hline Risk Category & Genetic Abnormality \\
\hline \multirow{4}{*}{ Favourable } & $\mathrm{t}(8 ; 21)(q 22 ; q 22.1) ; R U N X 1-R U N X 1 T 1$ \\
\hline & $\operatorname{inv}(16)(p 13.1 q 22)$ or t(16;16)(p13.1;q22); CBFB-MYH11 \\
\hline & Mutated NPM1 without FLT3-ITD or with FLT3-ITDlow \\
\hline & Biallelic mutated CEBPA \\
\hline \multirow{4}{*}{ Intermediate } & Mutated NPM1 and FLT3-ITDhigh \\
\hline & Wild-type NPM1 without FLT3-ITD or with FLT3-ITDlow (without adverse risk genetic lesions) \\
\hline & $\mathrm{t}(9 ; 11)(\mathrm{p} 21.3 ; q 23.3) ;$ MLLT3-KMT2A \\
\hline & Cytogenetic abnormalities not classified as favourable or adverse \\
\hline \multirow{10}{*}{ Adverse } & $\mathrm{t}(6 ; 9)(\mathrm{p} 23 ; q 34.1) ;$ DEK-NUP214 \\
\hline & $\mathrm{t}(\mathrm{v} ; 11 \mathrm{q} 23.3) ; \mathrm{KMT} 2 \mathrm{~A}$ rearranged \\
\hline & $\mathrm{t}(9 ; 22)(q 34.1 ; q 11.2) ; B C R-A B L 1$ \\
\hline & $\operatorname{inv}(3)(q 21.3 q 26.2)$ or $t(3 ; 3)(q 21.3 ; q 26.2) ;$ GATA2,MECOM(EVI1) \\
\hline & -5 or del $(5 q) ;-7 ;-17 / a b n(17 p)$ \\
\hline & Complex karyotype, monossomal karyotype \\
\hline & Wild-type NPM1 and FLT3-ITDhigh \\
\hline & Mutated RUNX1 \\
\hline & Mutated ASXL1 \\
\hline & Mutated TP53 \\
\hline
\end{tabular}

\section{RISK OF TRANSPLANT RELATED MORTALITY (TRM)}

It is accepted three different score systems for risk of TRM. These are HCT-Cl that utilizes 17 comorbidities with diverse weights ${ }^{[8]}$ and also adapted for reduced intensity conditioning regimens ${ }^{[9]} ; \mathrm{EBMT}^{[10]}$, and the combined $\mathrm{HCT}-\mathrm{Cl} / \mathrm{EBMT}^{[11-13]}$, all validated and accepted in this guideline. First CR favorable risk AML should not be submitted to HSCT when MRD is negative, however, if positive a SCT should be considered.

\section{HSCT SHOULD BE OFFERED TO AML PATIENTS IN SECOND CR.}

\section{Conditioning Regimens}

Myeloablative conditioning (MAC) regimens that combine a higher chance for engraftment with higher antileukemic activity, are ideal for AML patients younger than 55 years of age. Older age or the presence of comorbidities usually is an increased risk factor for TRM. ${ }^{[14]}$ Several studies including meta-analysis comparing Bu4/Cy with Bu4/Flu concluded that both MAC regimens have equivalent antileukemia effect with Bu4/Flu been less toxic. ${ }^{[15,16]} \mathrm{TBI}(\mathrm{Cy} / \mathrm{TBI})$ should be restricted for those patients with extramedullary disease. ${ }^{[17]}$ Fludarabine based RIC with alkylating agents should be chosen for elderly or those with comorbidities. When compared with MAC, RIC regimens are less toxic although a higher relapse rate is observed. ${ }^{[18-20]}$

\section{SOURCE OF STEM CELLS: BONE MARROW (BMSC) OR PERIPHERAL BLOOD (PBSC)}

Although in the matched related donor (MRD) scenario studies comparing BMSC and PBSC as a source for stem cells are inconclusive, chronic graft versus 
host disease (CGVHD) is higher and leads to worse quality of life for MAC MUR HSCT of PBSC; the latter should be utilized for patients with high risk disease receiving a MRD transplant. ${ }^{[21,22]}$ With faster neutrophils and platelets engraftment, and because inconclusive studies, PBSC is indicated for RIC transplants. [23] It should be noted that in the Brazilian experience, PBSC for myeloablative MRD transplants have been associated with significant higher incidence of cGVHD $^{[24]}$ leading to the Brazilian GVHD Study Group to recommend that the choice of SC source should be individualize according CGVHD risk.

\section{UNRELATED TRANSPLANTS}

Albeit retrospective, both CIBMTR and EBMT registries studies on MRD and MUD 10/10 HLA identical HSCT showed similar results. ${ }^{[25,26]}$ Although MUD transplants leads to a higher incidence of II-IV acute GVHD, TRM and OS are apparently similar to MRD transplants. Comparing MRD to MUD $8 / 8$ or $7 / 8$ HLA identical, although TRM is higher in the latter an increase in DFS at 3 years follow up, leaded to a similar OS. ${ }^{27}$ In the absence of a MUR 10/10 HLA identical, an $8 / 8$ donor is recommended and an $7 / 8$ can be acceptable. Pos transplant Cy (PTCy) associated to two immunosuppressors as GVHD prophylaxis either for MRD or MUD transplants looks promising. ${ }^{[28]}$

\section{HAPLOIDENTICAL SCT}

Haploidentical HSCT with PTCy GVHD prophylaxis ${ }^{[29]}$ is a good alternative for patients without an HLA matched donor since its related RR is similar to the TRM of an HLA 8/8 identical MUD transplant, leading to a comparable OS. ${ }^{[30]}$ On the other hand, a retrospective EBMT registry study including 10.679 patients submitted to either haplo or MRD transplant was not able to show a difference in RR probability. ${ }^{[31]}$ It is necessary to be aware that after PTCy haplotransplants, relapse can occur with leukemic cell losing its HLA molecules ${ }^{[32]}$, in which case DLI will be ineffective and if a second transplant is considered it should be from a different haploidentical donor. ${ }^{[33]}$

\section{HSCT FOR THE ELDERLY}

Overall, elderly AML patients have a worse prognosis. In addition to the frequent presence of comorbidities, high risk cytogenetic and molecular abnormalities are frequent in this patient population. The latter frequently contribute for remission induction failure, presence of MRD at best hematopoietic CR, and/ or shorter CR duration. ${ }^{[34]}$ It should be pointed out that the increasing population of healthy elderlies associated with the new target drugs and epigenetic agents for remission induction, when combined with TRM risk stratification and less toxic conditioning regimens are changing this scenario. ${ }^{[35-37]}$ In a recent CIBMTR study comparing MAC to RIC, OS was similar since the TRM of the first was comparable to the higher RR observed in the latter, in particular for Flu/Mel RIC. ${ }^{[38]}$

\section{HSCT FOR REFRACTORY/RELAPSED AML (R/R AML)}

HSCT in active AML disease patients is usually ineffective. In an EBMT registry study including 852 with $\mathrm{R} / \mathrm{R} A M L$, OS and DFS in two years was $30 \%$ and $25 \%$, respectively. ${ }^{[39]}$ In a smaller number of patients, the early utilization of sequential high dose chemotherapy and RIC regimen (FLAMSA-RIC) ${ }^{40}$ which rational is to avoid the utilization of several remission inductions schemes in the pursue of CR might be an alternative. In a recent metanalysis, FLAMSA-RIC tree years OS and DFS was $40,2 \%$ and $39,3 \%$, respectively, suggesting this treatment strategy might be a good option for these patients. ${ }^{[4]]}$

\section{AUTOLOGOUS HSCT}

Although autologous HSCT for AML remission consolidation is a moderately effective strategy, since $\mathrm{RR}$ is higher than allogeneic HSCT RR, ${ }^{[42,43]}$ however, it was shown in a recent metanalysis for intermediate risk AML patients without a related donor that autologous HSCT could be an option. ${ }^{[44]}$ Analyzing data from Brazilian HSCT Centers, Hamerschlak et al. ${ }^{45}$ found no difference in OS between allogeneic or autologous HSCT for AML. For low risk AML patients, autologous HSCT as a first CR remission consolidation might also be an option since when compared to chemotherapy consolidation only, results are not statistically different from allogeneic HSCT. ${ }^{[46]}$ For second $C R$ in acute progranulocyte leukemia (APL) consolidation, autologous HSCT is superior to arsenic trioxide. ${ }^{[47]}$

\section{MINIMAL RESIDUAL OR MEASURABLE DISEASE (MRD)}

Quantifying MRD became a key element in AML treatment strategy. The presence of MRD before allogeneic HSCT predicts pos transplant relapse, irrespective of AML risk category ${ }^{[48,49]}$ Multiparametric flow cytometry (MPF) MRD measurement is widely accepted and increasingly validated, provided laboratory expertise is available. ${ }^{[50]}$ RT-PCR, a method highly sensitive is only available for APL, Core Bind- 
ing Factors (CBF) or NPM1 AML mutations. ${ }^{[1]}$ According to ELN's recommendation, MDR measurement should be done before, 4 or less weeks before HSCT), and at three months thereafter for MPF, or at 4 to 6 months period for RT-PCR. The first should be done in bone marrow, and the latter in peripheral blood samples. ${ }^{[52]}$

\section{POST HSCT CR MAINTENANCE}

With the availability of target and epigenetic drugs, pos transplant maintenance is been studied actively. There are however several unanswered questions beyond efficacy. Pos HSCT period is very complex. The patient comes out from a profound neutropenia, transfusions, proper prophylaxis including GVHD's, and is frequently receiving antimicrobial and antiviral drugs. To determine the time to start maintenance without affecting engraftment, GVHD, or infection, and for how long maintenance should be administered are the main questions to be answered. Clinical trial results are just coming out of phase I or II with very few phase III studies.

Among the drugs been tested, sorafenib appears to be associated with favorable results when compared with historic controls ${ }^{[53-56]}$ and in some prospective randomized trials including a rather small number of patients, RR appears lower than the control arm without an impact in OS. ${ }^{[57]}$ As for midostaurin (RADIUS study) a randomized study comparing with no maintenance, did not showed a significant difference in RFS ${ }^{[58]}$ In phase I/II non-randomized studies on azacytidine results appears favorable, ${ }^{[59,60]}$ on the other hand, one prospective randomize study including 187 patients comparing azacytidine with no maintenance, no difference in RFS was observed. ${ }^{[6]]}$ While we await for results of several studies testing maintenance pos HSCT for AML, patients should receive it in the context of a clinical trial.

\section{NOTES ABOUT DONOR SELECTION}

The immunogenetic donor selection strategies for AML HSCT are described elsewhere in a specific chapter of this Brazilian Guideline for HSCT. In haploidentical transplants it should be stressed that at relapse, myeloblasts can have lost their HLA identity (HLA loss), in which case DLI or a new HSCT utilizing the same donor will be ineffective. Crucitti et al. described HLA loss in $33 \%$ of relapses. ${ }^{[62]}$ HLA loss can be detected by various methods such as myeloblast directed HLA typing, HLA-KMR or next generation sequencing (NGS). ${ }^{[63-66]} \mathrm{HLA}$ loss tests should be done at relapse.

All donors with HLA mismatch should be screened for the presence of donor specific antibody (DSA). If positive and the only possible donor, the patient should be desensitized.

Finally, myeloid neoplasms with germ line predisposition was included in the new WHO AML classification, and Hereditary Myeloid Malignancies Syndromes (HMMS) should be ruled out when there is previous history of cytopenia or family history of cytopenia or hematologic malignancies. Donors diagnosed with a pathogenic or likely pathogenic mutation in a HMMS related gene, even if asymptomatic, should be avoided. ${ }^{[67,68]}$

\section{RECOMMENDATIONS}

\section{HSCT Allogeneic (related or unrelated)}

1)HSCT allogeneic is indicated to $A M L$ high risk (A1). 2)HSCT allogeneic is indicated to AML in second completed remission (RC2) (A1).

3) HSCT allogeneic is indicated to AML intermediate risk, particularly in patients with MRD positive on RC1 (A1)

4)HSCT allogeneic is indicated to AML refractory/relapsed (C4).

\section{Conditioning Regimens}

1)Myeloablative conditioning is indicated to young patients, without significant diseases (younger than 55 years of age with $\mathrm{HCT}-\mathrm{Cl}$ equal or under than 2) (A1).

2)Older patients or with another disease should prefer reduced intensity conditioning (B2).

\section{Haploidentical SCT}

Level of evidence A2

Category recommendation: $\mathrm{B}$

\section{Autologous HSCT}

1)Indicated to AML low risk after 1 consolidation (C4) 2)Indicated to AML RC1 (according to the Brazilian experience) (C4)

3)Accept to APL second molecular remission (B2) 


\section{REFERENCES}

1.Niederwieser D, Baldomero H, Szer J, Gratwohl M, Aljurf M, Atsuta Y, et al. Hematopoietic stem cell transplantation activity worldwide in 2012 and a SWOT analysis of the Worldwide Network for Blood and Marrow Transplantation Group including the global survey. Bone Marrow Transplant; v. 51, p. 778-85, 2016.

2.D'Souza, A, Fretham C, Lee SJ, et al. Current Use of and Trends in Hematopoietic Cell Transplantation in the United States. Biol Blood Marrow Transplant. 2020 May 11:S1083-8791(20)302251, doi: 10.1016/j.bbmt.2020.04.013, PMID 32438042.

3.Passweg JR, Baldomero H, Basak GW, et al. The EBMT activity survey report 2017: a focus on allogeneic HCT for nonmalignant indications and on the use of non-HCT cell therapies. Bone Marrow Transplant; v. 54, n. 10, p. 1575-1585, 2019. doi:10.1038/s41409-019-0465-9.

4.Dohner H, Estey E, Grimwade D, Amadori S, Appelbaum FR, Buchner T, et al. Diagnosis and management of AML in adults: 2017 ELN recommendations from an international expert panel. Blood; v. 129, p. 424-47, 2017.

5.Grimm J, Jentzsch $M$, Bill $M$, et al. Prognostic impact of the ELN2017 risk classification in patients with $\mathrm{AML}$ receiving allogeneic transplantation. Blood Adv. v. 4, n. 16, p. 3364-3874, 2020. doi:10.1182/bloodadvances.2020001904.

6.Loke J, Malladi R, Moss P, Craddock C. The role of allogeneic stem cell transplantation in the management of acute myeloid leukaemia: a triumph of hope and experience. Br J Haematol; v. 188, n. 1, p. 129-146, 2020. doi:10.1111/bjh.16355.

7.Majhail NS, Farnia SH, Carpenter PA, et al. American Society for Blood and Marrow Transplantation. Indications for autologous and allogeneic hematopoietic cell transplantation: guidelines from the American Society for Blood and Marrow Transplantation. Biol Blood Marrow Transplant; v. 21, n. 11, p. 1863-1869, 2015.

8.Sorror M L, Maris M B, et al. Hematopoietic cell transplantation (HCT)-specific comorbidity index: a new tool for risk assessment before allogeneic HCT. Blood; v. 106, p. 106,. 2005.

9.Barba $P$, Piñana $J ~ L$, et al. Comparison of two pretransplant predictive models and a flexible $\mathrm{HCT}-\mathrm{Cl}$ using different cut off points to deter- mine low-, intermediate-, and high-risk groups: the flexible HCT-Cl is the best predictor of NRM and $O S$ in a population of patients undergoing allo-RIC. Biol Blood Marrow Transplant; v. 16, p. 413-420,. 2010.

10.Gratwohl A. The EBMT Risk Score. Bone Marrow Transplantation; v. 47, p. 749-756 2012.

11.Versluis J, Labopin M, Niederwieser D, et al. Prediction of non-relapse mortality in recipients of reduced intensity conditioning allogeneic stem cell transplantation with AML in first complete remission. Leukemia; v. 29, n. 1, p. 51-57, 2015.

12.Michelis FV, Messner HA, Atenafu EG, et al. Patient age, remission status and HCT-Cl in a combined score are prognostic for patients with AML undergoing allogeneic hematopoietic cell transplantation in CR1 and CR2. Bone Marrow Transplant; v. 50, n. 11, p. 1405-1410, 2015.

13.Sorror ML, Storer BE, Fathi AT, et al. Development and validation of a novel acute myeloid leukemia-composite model to estimate risks of mortality. JAMA Oncol; v. 3, 1675-1682 2017.

14. Heuser M, Ofran Y, et al. Acute myeloid leukaemia in adult patients: ESMO Clinical Practice Guidelines for diagnosis, treatment and follow-up. Annals of Oncology; 31, n. 6, p. 697-712, 2020.

15.Rambaldi A, Grassi A, et al. Busulfan plus cyclophosphamide versus busulfan plus fludarabine as a preparative regimen for allogeneic haemopoietic stem-cell transplantation in patients with acute myeloid leukaemia: an open-label, multicenter, randomized, phase 3 trial. Lancet Oncol; p. 1-12, 2015.

16.Ben-Barouch S, Cohen O, et al. Busulfan fludarabine vs busulfan cyclophosphamide as a preparative regimen before allogeneic hematopoietic cell transplantation: systematic review and meta-analysis. Bone Marrow Transplantation; $p$. 232-240, 2016.

17.Loke J, Malladi R, et al. The role of allogeneic stem cell transplantation in the management of acute myeloid leukaemia: a triumph of hope and experience. British Journal of Haematology; v. 188, p. 129-146, 2020.

18.Scott B L, Pasquini M C, et al. Myeloablative versus reduced-intensity hematopoietic cell transplantation for acute myeloid leukemia and myelodysplastic syndromes. J Clin Oncol; v. 35, p. 1154-1161, 2017. 
19.Craddock C. Conditioning intensity in HCT for AML: the jury is still out. Lancet; v. 5, p. 132-133, 2018.

20.Jethava Y S, Sica S. Conditioning regimens for allogeneic hematopoietic stem cell transplants in acute myeloid leukemia. p. 1-8, 2017.

21.M. Eapen, B.R. Logan, D.L. Confer, M. Haagenson, J.E. Wagner, D.J. Weisdorf, J.R. Wingard, S.D. Rowley, D. Stroncek, A.P. Gee, M.M. Horowitz, C. Anasetti. Peripheral blood grafts from unrelated donors are associated with increased acute and chronic graftversus-host disease without improved survival, Biol Blood Marrow Transplant; v.13, p. 1461-1468, 2007.

22.S.J. Lee, B. Logan, P. Westervelt, C. Cutler, A. Woolfrey, S.P. Khan, E.K. Waller, R.T. Maziarz, J. Wu, B.E. Shaw, D. Confer, M.M. Horowitz, C. Anasetti. Comparison of Patient- Reported Outcomes in 5-Year Survivors Who Received Bone Marrow vs Peripheral Blood Unrelated Donor Transplantation: Long-term Follow-up of a Randomized Clinical Trial. JAMA Oncol; v. 2, p. 43-50, 1583-1589, 2016.

23.Amouzegar A, Dey BR, Spitzer TR. Peripheral Blood or Bone Marrow Stem Cells? Practical Considerations in Hematopoietic Stem Cell Transplantation. Transfus Med Rev; v. 33, n. 1, p. 2019. doi: 10.1016/j.tmrv.2018.11.003.

24.Campregher PV, Hamerschlak N, Colturato VA, et al. Survival and graft-versus-host disease in patients receiving peripheral stem cell compared to bone marrow transplantation from HLA-matched related donor: retrospective analysis of 334 consecutive patients. Eur J Haematol; v. 95, n. 5, p. 421-5, 2015.

25.Saber W, Opie S, Rizzo JD, Zhang MJ, et al. Outcomes after matched unrelated donor versus identical sibling hematopoietic cell transplantation in adult's whit acute myelogenous leukemia. Blood; v. 119, n. 17, p. 3908-16, 2012.

26.Shimoni A, Labopin M, Savani B, Byrne M, Volin L, Finke J, et al. Comparable Long-Term Outcome after Allogeneic Stem Cell Transplantation from Sibling and Matched Unrelated Donors in Patients with Acute Myeloid Leukemia Older Than 50 Years: A Report on Behalf of the Acute Leukemia Working Party of the European Society for Blood and Marrow Transplantation. Biol Blood Marrow Transplant; v. 24, n, 11, p. 22512260 2019. doi: 10.1016/j.bbmt.2019.06.031.
27.Saber W, Opie S, Rizzo JD, Zhang MJ, et al. Outcomes after matched unrelated donor versus identical sibling hematopoietic cell transplantation in adult's whit acute myelogenous leukemia. Blood; v. 119, n. 17, p. 3908-16 2012.

28.Ruggeri A, Labopin $M$, Bacigalupo $A$, et al. Post-transplant cyclophosphamide for graftversus-host disease prophylaxis in HLA matched sibling or matched unrelated donor transplant for patients with acute leukemia, on behalf of ALWP-EBMT. J Hematol Oncol; v. 11, n. 1, p. 40, 2018. doi: 10.1186/s13045-018-0586-4.

29.Luznik L, O'Donnell PV, Symons HJ, et al. HLA-haploidentical bone marrow transplantation for hematologic malignancies using nonmyeloablative conditioning and high-dose, posttransplantation cyclophosphamide. Biol Blood Marrow Transplant; v. 14, n. 6. p. 641-50, 2008.

30.Ciurea SO, Zhang MJ, Bacigalupo AA, et al. Haploidentical transplant with posttransplant cyclophosphamide vs matched unrelated donor transplant for acute myeloid leukemia. Blood; v. 14, n. 6. p. 1033-1040, 2015.

31.Ringden O, Labopin M, Ciceri F, et al. Is there a stronger graft-versus-leukemia effect using HLA-haploidentical donors compared with HLA-identical siblings? Leukemia; v. 396 p. 4474552016.

32.Vago L, Perna SK, Zanussi M, et al. Loss of mismatched HLA in leukemia after stem-cell transplantation. NEng/ J Med; v. 396 p. 478, 2009.

33.Grosso D, Johnson E, Colombe B, et al. Acquired uniparental disomy in chromosome $6 p$ as a feature of relapse after T-cell replete haploidentical hematopoietic stem cell transplantation using cyclophosphamide tolerization. Bone Marrow Transplant; v. 52, p. 615, 2017.

34.Ossenkoppele G, Löwenberg B. How I treat the older patient with acute myeloid leukemia. Blood; v. 125, n. 5, p. 767-74, 2015.

35.Foran JM. Frontline therapy of AML: should the older patient be treated differently? Curr Hematol Malig Rep; v. 9, p. 100-8, 2014.

36.DiNardo CD, Jonas BA, Pullarkat V, Thirman MJ, Garcia JS, Wei AH, et al. Azacitidine and Venetoclax in Previously Untreated Acute Myeloid Leukemia. N Engl J Med; v. 383, n. 7, p. 617-629, 2020. 
37.Ustun C, Le-Rademacher J, Wang HL, et.al. Allogeneic hematopoietic cell transplantation compared to chemotherapy consolidation in older acute myeloid leukemia (AML) patients 60-75 years in first complete remission (CR1): an alliance (A151509), SWOG, ECOG-ACRIN, and CIBMTR study. Leukemia; v. 33, n. 11. p. 2599-2609, 2019. doi: 10.1038/s41375-019-0477-x.

38.Eapen M, Brazauskas R, Hemmer M, et al. Hematopoietic cell transplant for acute myeloid leukemia and myelodysplastic syndrome: conditioning regimen intensity. Blood Adv; v. 2, n. 16, p. $2095-2103,2018$. doi: $10.1182 /$ bloodadvances.2018021980.

39.Nagler A, Savani BN, Labopin M, et al. Outcomes after use of two standard ablative regimens in patients with refractory acute myeloid leukaemia: a retrospective, multicentre, registry analysis. Lancet Haematol; v. 2, p. 384-92, 2015.

40.Schmid C, Schleuning M, Ledderose G, Tischer J, Kolb HJ. Sequential regimen of chemotherapy, reduced-intensity conditioning for allogeneic stem-cell transplantation, and prophylactic donor lymphocyte transfusion in high-risk acute myeloid leukemia and myelodysplastic syndrome. J Clin Oncol; v. 23, p. 5675-87, 2005.

41.Owattanapanich W, Ungprasert $P$, Wais V, Kungwankiattichai S, Bunjes D, Kuchenbauer F. FLAMSA-RIC for Stem Cell Transplantation in Patients with Acute Myeloid Leukemia and Myelodysplastic Syndromes: A Systematic Review and Meta-Analysis. J Clin Med; v. 8, n. 9, p. 1437, 2019. doi: $10.3390 / \mathrm{jcm} 8091437$.

42.Cornelissen JJ, Versluis J, Passweg JR, et al. Comparative therapeutic value of post remission approaches in patients with acute myeloid leukemia aged 40-60 years. Leukemia; v. 229, p.1041-1050, 2015.

43.Saraceni F, Labopin M, Gorin NC, et al. Matched and mismatched unrelated donor compared to autologous stem cell transplantation for acute myeloid leukemia in first complete remission: a retrospective, propensity score weighted analysis from the ALWP of the EBMT. J Hematol Oncol; v. 9, p. 79, 2016.

44.Li Z, Liu Y, Wang Q, Chen L, Ma L, Hao S. Autologous Stem Cell Transplantation Is a Viable Postremission Therapy for Intermediate-Risk Acute Myeloid Leukemia in First Complete Remission in the Absence of a Matched Identical Sibling:
A Meta-Analysis. Acta Haematol. v. 141, n.3, p. 164-175.

45. Hamerschlak N, Barton D, Pasquini R, et al. Estudo retrospectivo do tratamento de leucemia mieloide aguda com o transplante de medula óssea: a experiência brasileira. Rev Bras Hemat Hemoter; v. 28, n.1, p. 11-8, 2006.

46.Schlenk RF, Taskesen E, van Norden Y, et al. The value of allogeneic and autologous hematopoietic stem cell transplantation in prognostically favorable acute myeloid leukemia with double mutant CEBPA. Blood; v. 122, n. 9, p. 1576-82, 2013.

47.Ganzel, C., Mathews, V., Alimoghaddam, K., et al. (2016). Autologous transplant remains the preferred therapy for relapsed APL in CR2. Bone marrow transplantation; 51 , n. 9, p. 1180-1183

48.Araki D, Wood BL, Othus $M$, Radich JP, Halpern AB, Zhou Y, Allogeneic Hematopoietic Cell Transplantation for Acute Myeloid Leukemia: Time to Move Toward a Minimal Residual Disease-Based Definition of Complete Remission? J Clin Oncol. v. 34, p. 329-336, 2015.

49.Buckley SA, Wood BL, Othus $M$, Hourigan CS, Ustun $C$, Linden $M A$, et al. Minimal residual disease prior to allogeneic hematopoietic cell transplantation in acute myeloid leukemia: a metaanalysis. Haematologica; v. 102, p. 865-73, 2017.

50.Schuurhuis GJ, Heuser M2, Freeman S, et al. Minimal/measurable residual disease in AML: a consensus document from the European LeukemiaNet MRD Working Party. Blood; v. 131, v. 12, p. 1275-1291, 2018.

51.Voso MT, Ottone T, Lavorgna S, Venditti A, Maurillo L, Lo-Coco F, et al. MRD in AML: The Role of New Techniques. Front. Oncol; v. 9, p. 1-10, 2019. (https://doi.org/10.3389/fonc.2019.00655).

52.Lee CJ, Savani BN, Mohty M, et al. Post-remission strategies for the prevention of relapse following allogeneic hematopoietic cell transplantation for high-risk acute myeloid leukemia: expert review from the Acute Leukemia Working Party of the European Society for Blood and Marrow Transplantation. Bone Marrow Transplant; v. 54, n. 4, p. 519- 530, 2019.

53.Chen YB, Li S, Lane AA, et al. Phase I trial of maintenance sorafenib after allogeneic hematopoi- 
etic stem cell transplantation for fms-like tyrosine kinase 3 internal tandem duplication acute myeloid leukemia. Biol Blood Marrow Transplant, v. 20, n. 12, p. 2042-2048, 2014.

54.Brunner AM, Li S, Fathi AT, et al. Haematopoietic cell transplantation with and without sorafenib maintenance for patients with FLT3-ITD acute myeloid leukaemia in first complete remission. Br J Haematol; v. 175, n. 3 p. 496-504, 2016.

55.Pratz KW, Gojo I, Karp JE, et al. Prospective study of peri-transplant use of sorafenib as remission maintenance for FLT3-ITD patients undergoing allogeneic transplantation. Biol Blood Marrow Transplant; v. 26, n.2, p. 300-306, 2020.

56.Battipaglia G, Ruggeri A, Massoud R, et al. Efficacy and feasibility of sorafenib as a maintenance agent after allogeneic stem cell transplantation for Fms-like tyrosine kinase 3-mutated acute myeloid leukemia. Cancer; v.123, n.15, p. 28672874, 2017.

57.Burchert A, Bug G, Finke J, et al. Sorafenib as maintenance therapy post allogeneic stem cell transplantation for FLT3-ITD positive AML: results from the randomized, double-blind, placebo-controlled multicentre Sormain trial. Blood; v. 132(suppl 1). Abstract 661.

58.Maziarz RTT, Patnaik MM, Scott BL, et al. Radius: a phase 2 randomized trial investigating standard of care +/- midostaurin after allogeneic stem cell transplant in FLT3-ITD-mutated AML. Blood; v. 132 (suppl 1). Abstract 662.

59.Platzbecker U, Wermke M, Radke J, et al. Azacitidine for treatment of imminent relapse in MDS or AML patients after allogeneic HSCT: results of the RELAZA trial. Leukemia; v. 26, n. 3, p.381-389, 2012.

60.Craddock C, Labopin M, Robin M, et al. Clinical activity of azacitidine in patients who relapse after allogeneic stem cell transplantation for acute myeloid leukemia. Haematologica; v. 101, n. 7, p. 979-883, 2016.
61.Oran B, de Lima M, Garcia-Manero G, et al. Maintenance with 5-Azacytidine for Acute Myeloid Leukemia and Myelodysplastic Syndrome patients. Blood; v132, p. 132 2018. Abstract 971.

62.Crucitti L, Crocchiolo R, Toffalori C, Mazzi B, Greco R, Signori A, et al. Incidence, risk factors and clinical outcome of leukemia relapses with loss of the mismatched HLA after partially incompatible hematopoietic stem cell transplantation. Leukemia; v. 29, p. 11430-52, 2015. doi: 10.1038/ leu.20 14.31429.

63.Vago L, Perna SK, Zanussi M, et al. Loss of mismatched HLA in leukemia after stem-cell transplantation. N Engl J Med; v. 361, p. 478-488, 2009.

64.Tsirigotis $P$, Byrne $M$, Schmid C, Baron F, Ciceri F, Esteve J, et al. Relapse of AML after hematopoietic stem cell transplantation: methods of monitoring and preventive strategies. a review from the ALWP of the EBMT. Bone Marrow Transplant; v. 51, p. 1431-38, 2016. doi: 10.1038/ bmt.2016.16738.

65.Ahci M, Toffalori C, Bouwmans E, Crivello P, Brambati C, Pultrone $C$, et al. A new tool for rapid and reliable diagnosis of HLA loss relapses after HSCT. Blood; v.130, p. 1270-3, 2017. doi: 10.1182/ blood-2017-05-7 84306 39.

66.Vago L, Ciceri F. Choosing the alternative. Biol Blood Marrow Transplant; v. 23, p. 1813-4, 2017. doi: 10.1016/j.bbmt.2017.09.00940.

67.Rafei H, DiNardo CD. Hereditary myeloid malignancies. Best Pract Res Clin Haematol; v. 32, n.2, p.2019. doi: 10.1016/j.beha.2019.05.001) (The University of Chicago Hematopoietic Malignancies Cancer Risk Team; How I diagnose and manage individuals at risk for inherited myeloid malignancies. Blood; v. 128, n.14, p. 1800-1813, 2016. doi: https://doi.org/10.1182/ blood-2016-05-670240

68.Godley LA, Shimamura A. Genetic predisposition to hematologic malignancies: management and surveillance. Blood. v. 130, p. 2017. 